Sociedades Precapitalistas, vol. 6, nº 2, e016, junio 2017. ISSN 2250-5121

Universidad Nacional de La Plata.

Facultad de Humanidades y Ciencias de la Educación.

Centro de Estudios de Sociedades Precapitalistas (CESP)

\title{
Reliquias y autoridad episcopal en el Irán Sasánida
}

\author{
Relics and episcopal Authority in Sasanian Iran
}

\section{Héctor R. Francisco *}

* Instituto Multidisciplinario de Historia y Ciencias Humanas-Consejo Nacional de Investigaciones Científicas y Técnicas. Facultad de Filosofía y Letras-Universidad de Buenos Aires, Argentinal Franciscohectorricardo93@gmail.com

\section{PALABRAS CLAVE RESUMEN}

Imperio sasánida

Cristianismo

Martirio

Hagiografía
Este trabajo analiza la relación entre episcopado y culto a las reliquias en el Irán sasánida. Al respecto, sostendremos que el culto a las reliquias contribuyó en el proceso de reconfiguración de la Autoridad episcopal en la Iglesia de Oriente iniciado por los sínodos del siglo V. En tal sentido, las tensiones generadas por el control de los santuarios cristianos no supusieron el enfrentamiento entre una elite laica y un episcopado plenamente diferenciado.

\section{KEYWORDS}

Sasanian Empire

Christianity

Martyrdom

Hagiography

\section{ABSTRACT}

This paper analyzes the relationship between episcopacy and the cult of the relics in Sasanian Empire. It will be argued that the cult of martyrs' relics contributed to the shift in the definition of episcopal Authority in the Church of the East in Fifth Century. In this regard, the tensions over the control of Christian shrines cannot be understood as an actual conflict between preexistent lay and clerical elites.

\section{Recibido: 31 de noviembre de 2016 | Aceptado: 5 de abril de 2017 | Publicado: 8 de junio de 2017}

Cita sugerida: Francisco, H. (2017). Reliquias y autoridad episcopal en el Irán Sasánida. Sociedades Precapitalistas, 6(2), e016._ 


\section{Introducción}

En la llamada “Gran persecución” dirigida por Sapor II contra los cristianos del imperio sasánida (340-344) miles de clérigos y laicos fueron obligados a optar entre ofrecer sacrificios de acuerdo a los ritos zoroastrianos o enfrentar el verdugo. Alrededor de un centenar de ellos fueron martirizados en la recientemente fundada residencia de verano de Sapor II en Karkhā d ${ }^{\mathrm{e}}$ Ledān. 1 Entre las víctimas más notables se encontraba Simeón Bar Șabba‘ē, obispo de Kōkhēê2 y “Católico” de la Iglesia del Oriente. $\underline{3}$ Simeón fue acusado de traición por haberse negado a recolectar un doble impuesto sobre todos los cristianos del imperio. Poco después de su ejecución, le siguieron otros miembros de la comunidad cristiana de Karkhā déLedān entre los que se destacaban el cautivo ${ }^{4}$ Pōsī y su hija Mārthā.

Una parte significativa de la historia de la “Gran persecución” bajo Sapor II está contenida en una colección de martirios relacionados con la muerte del Católico Simeón y sus compañeros. Estos son la Historia de

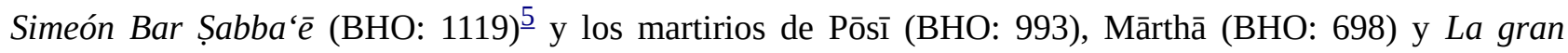
matanza de Bēth Hūzāyē (BHO: 704). Todas ellas circularon desde época más o menos temprana como una colección y es posible que fueran compuestas por un mismo autor. En virtud de su semejanza estilística y de contenidos, Wiessner (1967: 102) ha definido a este conjunto como el B-Zyklus $\underline{\underline{6}}$ (i.e. Ciclo B como lo llamaremos de aquí en adelante). Aunque los eventos narrados por el Ciclo B se ubican en la década del 340, la colección fue compuesta casi un siglo después, probablemente en la misma Karkhā d ${ }^{\mathrm{e}}$ Ledān. ${ }^{\underline{Z}}$ Como ha señalado Gernot Wiessner (1967: 102-105), dichos relatos fueron reinterpretados a la luz del contexto de centralización eclesiológica experimentado por la Iglesia de Oriente. Así una serie de características comunes a las narrativas contenidas en esta colección nos remiten a la voluntad de redefinir las bases sobre las que se sustentaba la autoridad espiritual. Entre ellas sobresalen tres; primero, la omnipresencia de los cautivos romanos como fuente de legitimidad espiritual. Segundo, el espacio dedicado en las narraciones a describir la circulación de las reliquias de los mártires. Por último, la preocupación por definir la autoridad legítima al interior de la comunidad cristiana.

Como mencionamos, la composición del Ciclo $B$ en las primeras décadas del siglo V se relaciona con dos fenómenos concurrentes. Por un lado, el proceso de reorganización de la Iglesia de Oriente de acuerdo a los cánones occidentales. Por otro lado, la proliferación de santuarios dedicados a la memoria de los mártires. Ambos procesos fueron concomitantes en la reconfiguración de la base de autoridad dentro de la comunidad cristiana. En tal sentido, estas narrativas implicaban una reescritura del pasado para ubicar en él las soluciones a las tensiones derivadas de aquella reconfiguración. Así, la composición de martirios estaba determinada por la progresiva integración de las elites cristianas del Irán occidental y Mesopotamia al contexto más amplio de las elites imperiales.

Este trabajo se propone analizar un aspecto particular de los martirios del Ciclo B, esto es, el traspaso de sus reliquias desde el ámbito familiar al control episcopal. Partimos de siguiente la hipótesis: dichas narrativas permiten observar como el culto a las reliquias de los mártires del siglo IV, institucionalizado entre las décadas del 420 y 440, contribuyó a transformar la dinámica de poder en el interior de las comunidades cristianas. En concreto, la "difusión” del culto de los mártires fue parte constitutiva de un proceso más amplio en el que se produjo una transformación en la relación entre la monarquía y las aristocracias cristianas.

En los siguientes apartados vamos a analizar la relación entre el culto a las reliquias y las estrategias de dominación aristocrática en el Ciclo B tomando como eje los martirios de Pōsī y Mārthā y otros textos análogos. En el primer apartado describiremos la secuencia que va desde la ejecución de los mártires hasta el establecimiento de las reliquias en un santuario familiar. Luego, analizaremos el proceso de transferencia de las reliquias a la autoridad episcopal. Este proceso de apropiación, sostendremos, no supuso el mero traspaso 
de un culto "privado" -i.e. controlado por la aristocracia laica- al ámbito "público" del poder episcopal (Brown, 1981: 9). Como intentaremos demostrar, la transformación de tumbas familiares en lugares de culto “cívico" fue parte de las tensiones resultantes del doble carácter del oficio episcopal. Esta tensión, contraponía dos lógicas diferentes (aunque no necesariamente antagónicas) de definirlo. Por un lado, un episcopado carismático identificado con la ciudad, sustentado en las redes de patronazgo derivadas del control de los santuarios locales y dependiente del consenso generado al interior de la elite cristiana. Por otro lado, el "oficio episcopal” dependiente de la integración de las comunidades locales a una red supraterritorial encabezada por el Católico de Kōkhē. Esta lógica se definía no tanto por la capacidad de los obispos de ejercer un patronazgo eficiente sobre la comunidad de fieles, sino por un nuevo marco normativo, derivado de la combinación entre patronazgo real y la introducción de los Cánones de la Iglesia romana en la Iglesia de Oriente.

\section{Reliquias y elites en el Ciclo B}

Las secciones finales de los martirios de Pōsī y su hija Mārthā están dedicadas a relatar el periplo de sus cuerpos desde su lugar de ejecución hasta su deposición en una iglesia local. Ambas secciones presentan una estructura común organizada en dos momentos. El primero comienza con la ejecución de los mártires y finaliza con la "apropiación” de sus cuerpos por parte de fieles locales (identificados como cautivos romanos), quienes los depositan en sus casas. El segundo momento, está dedicada a la Translatio de las reliquias del ámbito "familiar” al "episcopal”. Ambos momentos están separados por un hiato temporal más o menos extenso (tres generaciones) pero, desde el punto de vista de la continuidad narrativa, constituyen una misma secuencia.

De acuerdo con el texto de su martirio, Pōsī descendía de cautivos ( $b^{e}$ nay še bhīthā) que romanos, y era el jefe de los artesanos del rey. $\underline{8}$ En Karkhā déLedān, donde se había trasladado la corte real, Pōsī presenció la ejecución del Católico Simeón y los 102 clérigos y laicos que lo acompañaban. Ante el espectáculo de los mártires dirigiéndose alegremente al lugar de ejecución, el santo confesó públicamente su fe. Luego de interrogarlo, el rey ordenó su ejecución al día siguiente. Un día después fue apresada y ejecutada su hija Mārthā quien se negó a casarse para salvar su vida. $\underline{9}$ Los verdugos arrojaron los cuerpos del padre y su hija a la intemperie para ser devorados por los animales carroñeros, hasta que fueron rescatados por los fieles.

En líneas generales ambas narrativas reflejan los topoi convencionales de la literatura martirial, pero reelaborados a partir de las particularidades de su contexto iranio. Una de las más notables de esas particularidades se encuentra en las secciones finales, dedicadas al "rescate" de las reliquias por parte de los cristianos locales. Como ya hemos demostrado en otro lugar (Francisco: 2016), la forma y contenidos de estas narrativas -independientemente de su historicidad- se inspiraban en modelos bíblicos. La escena final del Martirio de Pōsī comienza señalando que los magistrados encargados de ejecutar al santo apostaron guardias para impedir que los fieles rescataran su cuerpo y lo transformaran en "una reliquia y una

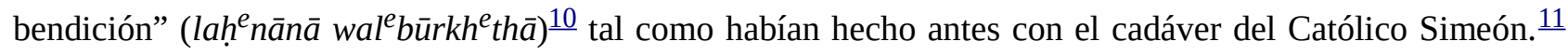
Pero la súbita caída de granizo espanto a los guardias, permitiendo a los fieles aproximarse y tomar el cadáver para trasladarlo a la ciudad. $\frac{12}{}$ Con este milagro comenzaba el derrotero del cuerpo del mártir que continua con su entrada en la ciudad envuelto en un saco y dispuesto sobre el lomo de un asno. Una vez dentro de la ciudad, otro portento reveló la casa de una dama cautiva que era "hija del pacto" (bath q $q^{e} y \bar{a} m \bar{a}$ ) como el lugar elegido para depositar el cuerpo. $\frac{13}{13}$ La dama y su hermano, identificándolo como su "conciudadano" (bar $m^{e} \overline{d i ̄}^{e}$ thōn), $\underline{14}$ lo aceptaron como "un don (māwhabhthā) del Señor que les era enviado" y "lo depositaron (en la casa) con honores, para que sea un tesoro de bendición (sīme thā $d^{e} b \bar{u} r k^{e}$ thā) para sus conciudadanos (lab ${ }^{e}$ nay $m^{e}$ dìthāh)”. $\underline{15}$ 
El vocabulario de la sección final del Martirio de Pōsī nos permite identificar con mayor precisión la lógica subyacente a ellas. En efecto, los huesos de los mártires son descriptos como una "una reliquia y una bendición” (laḥ ${ }^{e}$ ānā wal ${ }^{e} b u \bar{r} k h^{e}$ thā) ofrecidos como un "don” (māwhabhthā) por Dios a la familia depositaria de las reliquias. Ambas expresiones, nos remiten a un "vocabulario técnico" del discurso hagiográfico. Daniel Caner (2006) ha analizado dicho vocabulario a partir de la noción de "economía milagrosa” desarrollado por Vincent Déroche (1995). Caner inscribe la circulación de reliquias en el marco más amplio de un ideal económico en el que la riqueza conferida por Dios debía ser puesta en circulación a través de la caridad. En el cercano Oriente tardo-antiguo, dichas "bendiciones” (en griego eulogiai en siríaco būrkh ${ }^{e}$ thā) eran pequeños dones confeccionados con partes del cuerpo de los mártires u objetos que estuvieran en contacto con ellos mezclados con agua y aceite. Este tipo de don cristiano supuso una ruptura con respecto a las formas tradicionales del mundo greco-romano ya que "[...] was believed to originate with God, that made no demands on its receiver, and that could be used to support Holy people, or to confer Holiness when given” (Caner, 2006: 334)..$^{16}$ Este tipo de dones no estaban pensados para su acumulación sino para su circulación en tanto no suponían necesariamente la obligación de una retribución inmediata, sino que operaban en la construcción de lazos sociales en la medida que -por su intermedio- el donante entregaba una parte de sí al donatario. En otras palabras, el rescate y la transformación de los cuerpos en "reliquias y bendiciones" se asemejaba a una forma de Inventio reliquiarum cuyo efecto era transmitir la autoridad espiritual de los mártires a sus custodios. El texto del Martirio de Pōsī deja en claro la dimensión comunitaria de las reliquias al definirlas como un "tesoro" ( $\operatorname{sim}^{e}$ th $\left.\bar{a}\right)^{\frac{17}{17}}$ destinado a favorecer a toda la comunidad.

La sección final del Martirio de Mārthā atribuye una duplicidad similar a las reliquias. El cuerpo de la joven fue dejado a la intemperie y custodiado por guardias hasta que fue rescatado gracias a "un soborno (šụḥda ${ }^{18}$ )”. Luego, “el hermano de la bienaventurada que había sepultado a su padre, había provisto el dinero y se había llevado el cadáver, y también lo ungió y la depositó con su padre”. $\underline{19}$ A diferencia del caso de Pōsī, el rescate de Mārthā no incluye ningún elemento sobrenatural que simbolice la voluntad divina de conceder las reliquias a la familia sino que es el soborno el que habilita el rescate. Este cambio en el énfasis no es menor. Si los sucesivos milagros en la historia de Pōsī señalan que es el mismo Dios quien ha otorgado el control de sus restos a los hermanos, en la historia de Mārthā tal insistencia se hacía, en apariencia, redundante. A pesar de su tono mundano, el rescate del cuerpo de Marthā resulta revelador en tanto el topos hagiográfico deja lugar a una descripción más vívida que describe sin ambages el interés de los notables locales por apoderarse de las reliquias al punto de llegar al soborno.

Esta preocupación por "recuperar" las reliquias se reproduce en el resto de los textos del Ciclo B. La Historia de Simeón bar Șabba ‘ē refiere que los fieles se apresuraron a recolectar los cuerpos del Católico y sus compañeros para enterrarlos. $\underline{20}$ En La Gran Matanza de Bēth Hūzāyē se narra que el mismo rey exigió que recuperaran el cuerpo de su favorito, el eunuco cristiano Azād. $\underline{21}$ Otros textos relacionados con el Ciclo $B$ también refieren cómo los cristianos recogían con la avidez reliquias de los mártires para llevarlos a sus casas. El Martirio de los 120 mártires (BHO: 718) ejecutados circa 345 en la ciudad de Ctesifón describe que los cristianos encerrados en la prisión recibieron el cuidado de una noble dama llamada Yazdāndūkht. $\underline{22}$ Una vez ejecutados, la dama contrató a “unos hombres del mercado” (gabrē men šūqā) quienes tomaron los cuerpos por la noche. Allí, la dama los vistió con vestimentas blancas y ordenó que los sepultaran en una fosa (hephrā) en las afueras de la ciudad. $\underline{23}$ En este último caso, aunque no hay referencia alguna a que la dama financiara la construcción de un santuario para alojar las reliquias, Yazdāndūkht se transformó en un verdadero modelo de la relación íntima entre la aristocracia cristiana y los mártires de la "Gran persecución” (Peeters, 1925: 292) $\underline{24}$ Por su parte, las historias de Mār Qardagh (BHO: 555) y Mār Sabā (BHO: 1031) 
ofrecen interesante información del establecimiento de santuarios rurales en las propiedades de familias aristocráticas (Payne, 2011: 106).

Ubicadas en este contexto, las historias de Pōsī y Mārthā dan cuenta de la centralidad de las reliquias de los mártires como fuente de prestigio para la aristocracia cristiana. En tal sentido, podemos relacionar la actitud de la familia que alojó los cuerpos de los mártires con el concepto de “mercancías sagradas” (Sacred Commodities) utilizado por Patrick Geary (1988) para definir la circulación de reliquias en la Edad Media. Estas mercancías sagradas estaban destinadas a la circulación a través de variados mecanismos que iban desde la donación, la venta hasta el robo. Geary, siguiendo a Brown (1982: 238-239) sugiere que la instalación de las reliquias en una determinada comunidad o el establecimiento de la fiesta en su honor era la "prueba crucial” de los alineamientos dentro de ella ya que, como vimos, su circulación implicaba la transferencia de la autoridad espiritual.

Este aspecto de las reliquias como constituyente de las relaciones de poder al interior de la Iglesia está relativamente bien documentado en el Oriente romano. En su estudio comparativo de los testimonios existentes acerca del establecimiento del santuario dedicado a las reliquias de San esteban en el santuario a las afueras de Jerusalén, Elizabeth Clark (1982) ha descripto cómo las diversas narrativas referidas a la construcción del santuario reflejaban la competencia entre los partidarios de la emperatriz Eudocia y la noble dama romana Melania por legitimar su relación de los huesos del protomártir. En este caso, la disputa determino la mirada acerca del papel de ambas mujeres (y de los arzobispos de Jerusalén, Juvenal y Alejandría, Cirilo) en el establecimiento del santuario. Por otra parte, la intervención (real o ficticia) de los prelados parecen haber sido secundaria revelando que, lejos de aspirar al monopolio del control de las reliquias, estos participaban en el conflicto intra-aristocrático confiriendo legitimidad a cada una de las partes.

Pero las reliquias no eran meros objetos de prestigio, además las fiestas anuales en honor de los santos eran ocasiones en las que el patronazgo aristocrático (mediado por el obispo) se manifestaba en la comunidad. De hecho, como ha demostrado Richard Finn (2006), el prestigio de un obispo descansaba en su capacidad de recolectar bienes que eran redistribuidos en fundaciones caritativas como hospicios y hospitales. De esta manera, los obispos funcionaban como "recaudadores de fondos" que dependían de la colaboración de las elites para encauzar la circulación de la riqueza.

Este tipo de prácticas se proyectaron en el mundo iraní a través de la estrecha vinculación entre santuarios y propiedad aristocrática. Richard Payne (2011: 102-108) ha analizado los testimonios relativos al establecimiento de santuarios cristianos en las residencias de la aristocracia tanto en las ciudades como en el ámbito rural. Payne afirma que dichas fundaciones aristocráticas surgieron como una estrategia en la competencia entre clero, monjes y laicos por utilizar un recurso esencial en la constitución de la identidad comunitaria. Las historias de Pōsī y Mārthā reflejarían esa estrategia que no sólo les permitía construir su prestigio personal, sino que además contribuía a afianzar el patrimonio familiar. No existen testimonios directos que nos permitan reconstruir los detalles de las estrategias patrimoniales subyacentes a estas fundaciones. Pero las frecuentes alusiones a litigios en torno a la propiedad de los santuarios entre herederos -como la misma historia de Pōsī y Mārthā o el Martirio de Narsaï (BHO: 786) $\underline{25}$ - sugieren un paralelo con una forma similar de fundaciones piadosas zoroastrianas designadas fundaciones "por las almas" (en persa medio Xwastag pad ruwān) análogas al waqf islámico (Boyce 1968). $\underline{26}$ Este tipo de propiedades colectivas aseguraban la continuidad y la inalienabilidad de las propiedades puestas bajo esta categoría, inmovilizando así el patrimonio de un linaje en un contexto en el que la disponibilidad de herederos varones no estaba asegurada.

El establecimiento de estas fundaciones piadosas ligadas a los linajes aristocráticos no se limitaba a 
santuarios de los mártires, sino que además se extendían al establecimiento de todo un abanico de espacios (monasterios, escuelas y hospitales) que formaban parte integral de la vida de las comunidades cristianas, en particular en las ciudades. En dichos espacios las aristocracias materializaban sus redes de patronazgo sobre la comunidad de fieles y así cimentar su prestigio a partir de la redistribución de la riqueza. La Historia de Karkhā d-Bēth Slōkh narra las historias de los obispos del siglo V 'Aqeblāhāํㅡㅁ y Šabōr Braz ${ }^{\underline{28}}$ quienes representan un modelo de obispo aristócrata que combinaba los recursos familiares y oficio episcopal. Mientras que el primero utilizó sus recursos como terrateniente para reconstruir las iglesias destruidas durante el siglo IV, el segundo fundó el hospicio local. Ambas fundaciones son presentadas como donaciones desinteresadas integradas a la Iglesia, pero la comunitaria vinculaba indisolublemente dichos espacios al linaje. En otras palabras, mientras que el oficio podía dar expresión formal al liderazgo comunitario, el control sobre los santuarios le daba su sustento material. Hacia la segunda mitad del siglo VI se percibe con claridad el conflicto latente en torno a la naturaleza de dichas fundaciones. En efecto, los cánones de los sínodos de Mār José (554) y Mār Ezequiel (576) $\underline{29}$ se orientaban a proteger la propiedad eclesiástica de los reclamos de la aristocracia, prohibiendo el recurso a "los tribunales de los ajenos (i.e. zoroastrianos)" para dirimir asuntos internos de la Iglesia (Payne 2015: 107). Sin embargo, las fuentes anteriores al catolicado de Mār Abā (540-552) son sugestivamente silenciosas al respecto. En el próximo apartado analizaremos la intrínseca relación entre la reconfiguración del poder episcopal en la primera mitad del siglo V y su relación con el culto a las reliquias.

\section{Obispos, reliquias y los fundamentos del liderazgo cristiano}

Dada esta interrelación entre santuarios y episcopado, no debería sorprendernos que ambas realidades fueran objeto de la competencia en el seno de las elites locales. Naturalmente, este tipo de conflictos rara vez aparecen representados nítidamente en la hagiografía y, por lo general, eran encubiertos por artilugios narrativos. Pero la recurrencia de menciones a las intromisiones de los laicos en los asuntos eclesiásticos en los cánones de los sínodos de los siglos V y VI permite deducir su importancia. No obstante, estos conflictos no pueden describirse desde la oposición lineal entre clero y laico. Por el contrario, en una situación de indeterminación efectiva entre ambas categorías, una distinción tal era una forma de deslegitimar a los rivales.

En los martirios de Pōsī y Mārthā la transferencia de las reliquias desde el ámbito familiar al episcopal implica una resignificación de ambas realidades. En efecto, a pesar del carácter familiar del santuario de los mártires, su culto es invariablemente asociado al ámbito eclesiástico. El autor destacaba que la conmemoración periódica de la fiesta de los santos era realizada por la familia, pero "en presencia de los sacerdotes eclesiásticos” ( $b^{e}$ qarībūthā d kahne $b^{e}$ nay 'edtā) legitimando la liturgia. Esta función legitimante del clero es también evidente en el periplo de los cuerpos hasta su lugar de descanso final:

Y después de su partida (i.e. la muerte de la mujer), su morada pasó al hijo de su hermano que también realizaba su conmemoración con diligencia como era la costumbre de la bienaventurada. Y cuando partió el hijo de su hermano, pasó a sus dos hijos. Y luego de un tiempo de su partida, hubo una disputa sobre los huesos de los santos. Y uno de ellos deseaba dividirlos entre él y su hermano que le había tocado en su parte la casa de la bienaventurada. Y el asunto fue del conocimiento de Șaūmaī el obispo de Karkhā, de bella memoria, quien convenció a los dos (hermanos) y los tomó (i.e. a los huesos) de ellos. Y se los dio a los eclesiásticos de Karkhā (lab nay 'edtā d'Karkhā), para que sean bella memoria ('ūhdānā) y valioso tesoro (sīme thā $m^{e}$ yatarthā) para la Iglesia del Mesías. Esto fue realizado por el santo obispo Șaūmaī en el octavo año del rey Barhārān bar Yazdgard $\underline{30}$ (428) 89 años después de su coronación (i.e.de los mártires). $\underline{31}$ 
A primera vista, el fragmento parece describir simplemente la transmisión de las reliquias del santuario familiar a una iglesia bajo control del obispo. Pero los detalles sugieren una realidad más compleja. El conflicto en cuestión no es la competencia entre clero y laicos por el control sobre las reliquias sino una disputa en el seno de la familia misma. En este contexto, la resolución carece de sentido. En efecto, ¿cómo puede satisfacer a las partes esta suerte de "tercera vía” que lleva a la apropiación de las reliquias por el obispo? El traspaso de las reliquias no es su simple relocalización sino también la transferencia de un recurso fundamental para asegurar el consenso en el seno de la comunidad. Así, cabe preguntarse acerca de la naturaleza de esta intervención. ¿Acaso el obispo Șaūmaī actuaba en tanto una realidad superior al cuerpo de creyentes? Ciertamente, el obispo transfería una herramienta de prestigio social fundamental desde el ámbito familiar al ámbito episcopal. A primera vista sus acciones responderían a su interés -en tanto obispo- por monopolizar la administración de las reliquias. Sin embargo, toda la escena dista de ser clara. ¿Pudo haberse dado la transferencia sin conflicto?, ¿acaso el hagiógrafo silenció la resistencia de los hermanos?, ¿acaso ellos fueron testigos pasivos o la transferencia respondía a sus intereses?

Creemos que la clave para comprender mejor la naturaleza de la transferencia se encuentra en otro texto martirial en el que Șaūmaī intervino de manera similar. En el Martirio de Jacobo el notario (BHO 412), ejecutado circa 422, Șaūmaī reaparece como apropiador de las reliquias del santo en poder de una familia. En el episodio final del martirio, los hombres que habían rescatado su cuerpo en Seleucia y Ctesifón lo llevaron hasta la madre del mártir, quien recurrió al obispo para enterrarlo. Ambos lo depositaron "en un lugar honroso ( $b^{e}$ dūkthā $h^{e} d \bar{a} m^{e}$ yaqarthāa)". El texto concluye señalando que la dama "Preparó todo lo necesario para el banquete, $\underline{32}$ hizo una conmemoración del victorioso, y (allí) eran recibidos los santos, las viudas, los pobres y los mendigos”. $\underline{33}$ El testimonio del Martirio de Jacobo el notario presenta dos notas de interés. Primero, nunca se hace mención explícita a santuario alguno, sino a través de circunloquios "un lugar honroso”, “una conmemoración”. La reluctancia a definir el lugar de depósito de las reliquias podría relacionarse con la incertidumbre por la naturaleza del lugar donde se encontraban (Payne, 2011: 98). Segundo, Șaūmaī no intervino como mediador en un conflicto sino como legitimador de la iniciativa familiar que hizo del santuario un espacio en el que se manifestaba el patronazgo sobre la comunidad.

Ambos casos muestran que la intervención episcopal se produce a instancias (y no en contra) de la elite laica. De la lectura atenta del episodio se desprende que la naturaleza de las acciones de Șaūmaī no se explica por el conflicto o la negociación entre una elite laica y el episcopado sino en el papel mediador del oficio episcopal. Este papel mediador del obispo, veremos, deriva de una transformación del oficio episcopal. Dicha transformación fue el resultado del proceso de centralización política entre los siglos V y VI y que afectó las bases mismas sobre las que se asentaba el poder episcopal.

A partir de las primeras décadas del siglo V los monarcas sasánidas ejercieron un creciente control sobre el clero cristiano, al mismo tiempo que delegaron en los obispos algunas formas de autoridad (judicial, administrativa y fiscal) dentro de la comunidad de fieles. $\underline{34}$ Por supuesto, esto no suponía una autonomía de la Iglesia con respecto a la monarquía y mucho menos la separación entre comunidades religiosas. Por el contrario, en tanto súbditos del Šāhānšāh, los cristianos del imperio estaban sujetos a su "jurisdicción” a través de sus delegados. Como en cualquier sistema pre-moderno en el que la esfera civil y religiosa no están plenamente diferenciadas, el derecho y la administración sasánidas estaban imbuidos de una impronta religiosa derivada del Avesta, y tanto la burocracia como los jueces (dādwarān) eran reclutados entre los especialistas en la religión zoroastriana (mowbedān). No obstante, el monopolio de la elite religiosa zoroastriana sobre la administración y el sistema legal distaba de ser absoluto. Los obispos cristianos también podían actuar, con ciertas limitaciones, como una suerte de justicia en primera instancia, agentes fiscales o incluso como diplomáticos (McDonough, 2008a: 89). 
En este contexto, no es sorprendente que las narrativas pertenecientes al Ciclo B muestren un marcado interés por definir la autoridad de los obispos. De acuerdo con la Historia de Simeón Bar Șabba‘ēe el Católico distinguía su autoridad de la del rey en tanto el obispo ejercía una autoridad puramente espiritual sobre su rebaño. Además, el mártir equiparaba la obediencia a Dios y la obediencia al rey de reyes en tanto una era inconcebible sin la otra. $\underline{35} \mathrm{Al}$ mismo tiempo, el Católico se definía a sí mismo y su comunidad como “pobres” (meskanē) pero cuyas “propiedades” (qenyānan) estaban a disposición del rey. $\underline{36}$ La Historia de Simeón Bar Șabba'ē no hace referencia explícita a propiedades eclesiásticas pero otros textos hagiográfico rebelan la ambigüedad y el solapamiento entre éstas y las posesiones de la aristocracia laica. $\frac{37}{}$ Rara vez las fuentes revelan conflictividad, pero, en algunos casos, dicha ambigüedad presupone tensiones. El Martirio de 'Aqebšemā y sus compañeros relata que cuando el obispo y mártir se dirigía al tribunal para ser interrogado y ejecutado, uno de sus allegados le requirió que designara alguien para "cuidar su casa (mezdhar $b^{e}$ baytākh) para que no sea saqueada". Pero el santo se negó aludiendo que "esta casa no es mi casa y esta propiedad (qenyānā) no es mi propiedad, pues el mesías me la heredó, para que su pueblo no necesite nada". $\underline{38}$

La tensión entre las propiedades de los obispos procedentes de la elite local y las propiedades "eclesiásticas" se extendía a la circulación de las reliquias. $\frac{39}{}$ Retomando nuestra pregunta inicial ¿en virtud de qué poderes el obispo Șaūmaī se apropió de las reliquias? Disimulado como un desinteresado arbitrio subyace una estrategia que se inscribe en un movimiento más amplio caracterizado por el deliberado intento del oficio episcopal sino como una estrategia de las mismas elites que estabilizaban la circulación de reliquias y minimizaban así los efectos de la competencia interna. En tal sentido, el período transcurrido desde la ejecución de los mártires hasta su definitiva deposición a una iglesia local explica las necesidades de la elite local por crear un espacio diferenciado.

En nuestro caso, esto es evidente si tomamos en cuenta que el objeto de la disputa entre ambos hermanos no era el espacio donde se ubicaban las reliquias sino los huesos que éste contenía. Así, el espacio sagrado es definido por la presencia de las reliquias, y su transferencia supone el traslado de la santidad a un nuevo espacio (Markus 1994). Dicho espacio no es identificado materialmente, aunque podemos deducir legítimamente que se trataba de una iglesia. Por el contrario, ese nuevo espacio es definido a partir de la distinción entre el espacio de los “eclesiásticos” o “clérigos” ( $b^{e}$ nay ‘edtā) que alude a una categoría especial que se opone a los “laicos” ( $b^{e}$ nay ‘ālmā).

A pesar de que esta polaridad entre clero/laico que articula la transferencia espacial no era desconocida en la Iglesia de Oriente del siglo IV esta parece haberse desarrollado y profundizado en el siglo V. En tal sentido, cabría preguntarse en qué medida la apropiación de los huesos de los mártires por parte del obispo local supuso una competencia entre una elite laica y una elite episcopal previamente constituidas o si refleja un cambio en la constitución del episcopado. Para responder este interrogante primero debemos establecer la relación entre las narrativas de los martirios y su contexto de producción en la primera mitad del siglo V, momento caracterizado por una profunda reorganización de la Iglesia de Oriente.

\section{Narrativa y organización episcopal: el papel de las reliquias de los santos}

Como dijimos, los casos de Pōsī y Mārthā ubican los eventos en la ciudad de Karkhā d ${ }^{\mathrm{e} L e d a ̄ n ~ a ~ m e d i a d o s ~ d e ~}$ la década del 340. Sabemos poco de la comunidad cristiana de la ciudad con anterioridad al segundo cuarto del siglo V, pero los desarrollos durante el siglo siguiente sugieren un proceso de formalización de la comunidad que implicó la imposición de un episcopado monárquico vinculado a una red supra-territorial en cuya cabeza se encontraba el Católico de la capital imperial. En este apartado nos ocuparemos de un doble 
proceso. Primero, haremos una breve reseña de la historia de la ciudad y de los cambios que experimentó en la primera mitad del siglo V. Estos cambios estaban en relación con transformaciones más amplias que experimentó la Iglesia del Oriente en su conjunto. Finalmente, precisaremos el tipo de relación que existe entre esos cambios y la composición del ciclo de martirios en general y de los martirios de Pōsī y Mārthā en particular.

El canon XXI del sínodo de Mār Isaac (410) menciona al obispado de Karkhā de Ledān como diócesis sufragante de la metrópolis de Bēth Hūzāyē, en el extremo sudoccidental del actual Irán. $\underline{40}$ El metropolita de Bēth Hūzāyē se encontraba en la ciudad de Gūndīšāpūr/Bēth Lapaț, que era la segunda metrópolis después del Católico en el orden de preeminencia en la Iglesia de Oriente (Fiey, 1969 y 1970). El obispo de Karkhā d ${ }^{\mathrm{e}}$ Ledān era el segundo en la lista de preeminencia dentro de la diócesis, pero casi nada se sabe antes de la ciudad con anterioridad al siglo V (Fiey, 1970).

Uno de los obispos mejor conocidos de la ciudad es Șaūmaī a quien ya hemos mencionado. Ṣaūmaī fue un protagonista activo de las transformaciones ocurridas en la Iglesia de Oriente durante el siglo V. En efecto, estuvo entre los signatarios del sínodo de Mār Yahbāllāhā (420) que incorporó los cánones occidentales en lo relativo a la disciplina eclesiástica. $\underline{41}$ Como vimos, además fue un activo promotor del culto local de los santos, tanto de Simeón, como de Jacobo el Notario, de Pōsī y Marthā (Fiey, 1970: 127). No parece casual que este obispo sea mencionado en varios textos martiriales. Menos sorprendente es que el Ciclo B haya sido probablemente compuesto bajo su autoridad.

Ṣaūmaī ocupó su sede durante el clima reformador de las primeras décadas del siglo V. Durante esos años se reunieron los tres primeros grandes sínodos de la Iglesia de Oriente, $\underline{42}$ que no sólo establecieron a la ortodoxia nicena en el imperio persa sino que además contribuyeron a la formalización de una estructura episcopal de acuerdo a los cánones occidentales. Esta reorganización de la Iglesia de Oriente no se limitó a fijar el orden de preeminencia entre las sedes episcopales bajo la primacía del Católico de Kōkhē, sino que, sobre todo, sometió formalmente la autoridad eclesiástica a la tutela del monarca. El mismo rey de reyes Yazdgard I (399-420 AD) fue responsable de la convocatoria del sínodo del año 410, que fue copresidido por el Católico Isaac y el embajador romano, el obispo Marūthā de Maīpherqaț. $\underline{43}$ Con estos concilios, Yazdgard no solo legalizó el culto cristiano sino que además fue capaz de establecer un patronazgo efectivo sobre la Iglesia, integrándola al espacio cortesano (McDonough, 2008b).

Ese proceso de integración de la Iglesia a la corte real se inscribió en una dinámica más amplia, caracterizada por la tensión entre el Šāhānšāh por un lado y la elite religiosa zoroastriana y las grandes casas aristocráticas (wuzurgān) por el otro. Podemos sintetizar esta tensión en la pretensión del monarca por afianzar su autoridad mediante el despliegue de un patronazgo real que ampliaba su base de poder a los estratos inferiores de la elite (entre los cuales se encontraban judíos y cristianos) y las resistencias que este despliegue generaba. En concreto, la política religiosa tolerante de Yazdgard I parece haberse alejado de la política de hostilidad de su abuelo Sapor II. Este cambio de política permitió que las fuentes cristianas hicieran una contraposición retrospectiva de ambos monarcas apelando a una dicotomía que se asemejaba a la ya establecida en occidente entre Diocleciano y Constantino (McDonough, 2008b). Pero este paralelismo entre los reyes sasánidas y sus contrapartes romanas no fueron más que artilugios literarios de los hagiógrafos para adaptar a las realidades de la Iglesia sasánida el modelo occidental (i.e. eusebiano) de relación entre los cristianos y la monarquía (McDonough, 2006). Aunque el zoroastrismo era, desde el punto de vista religioso, un elemento central en la ideología imperial, la relación entre los monarcas y el zoroastrismo fue mucho más fluida de lo que se suele reconocer (McDonough, 2011). En tal sentido, el zoroastrismo no era una "religión de Estado” y la monarquía sasánida (a diferencia de su colega romano) nunca exigió uniformidad religiosa por parte de la totalidad de sus súbditos. En tal sentido, las medidas represivas de Sapor II no parecen haber 
tenido por objetivo "eliminar" una determinada forma de disidencia religiosa. Por el contrario, resulta probable que fuera el efecto de la integración de la elite cristiana al marco cortesano (Payne, 2015: 23-58). No obstante, esta actitud flexible no implicaba "tolerancia" en el sentido moderno del término (Becker, 2014).

Puesta en diálogo con este contexto más amplio de la penetración de la monarquía en los márgenes (geográficos, culturales o religiosos) del imperio, la reorganización de la Iglesia de Oriente tiene para nosotros un significado adicional. Desde el siglo III, el episcopado había sido un fenómeno primariamente local. Es indudable que en el siglo IV la monarquía había intervenido en las comunidades cristianas, mediante los mismos mecanismos de patronazgo que desplegaba con otras comunidades religiosas (entre las más notorias, maniqueos, magos y judíos). Pero los alcances parecen haber sido limitados. En ese contexto, la autoridad de un obispo tanto frente a su rebaño como frente a sus colegas derivaba de variables que cambiaban de acuerdo al contexto. Pero no parece haber existido una institucionalización y jerarquización del oficio episcopal comparable a la que se desarrolló en occidente en el siglo IV. Cualquiera sea su vinculación con los notables locales, desde el siglo $\mathrm{V}$ en adelante el poder de los obispos fue progresivamente dependiente de su inscripción en una red de solidaridad y obediencia que se desplegaba territorialmente hasta la cúspide en la capital imperial.

La conformación de una estructura jerárquica y una institucionalización del oficio episcopal parece haber sido el efecto de la adopción de los cánones de los concilios occidentales a lo largo del siglo V (Jammo, 1995), pero que no se afianzó hasta la segunda mitad del siglo VI (Jullien, 2008), (Payne, 2015: 93-126). Aunque la incorporación de los sínodos occidentales se produjo como un bloque, su proyección en los cánones de los sínodos de la Iglesia de Oriente refleja un recorte específico, determinado por la preocupación por la construcción del oficio episcopal. Todo el proceso de formalización del oficio episcopal fue acompañado -o incluso fomentado- por la autoridad real. No podemos afirmar con absoluta seguridad que se haya tratado de un plan sistemático o consciente, ni que el proceso fuera lineal. Sin embargo, un efecto fundamental de este proceso fue la emergencia de una nueva lógica de reclutamiento y ejercicio del oficio episcopal: su inscripción en redes supra-locales que vinculaban a las comunidades con un centro (la sede patriarcal) que mediaba entre estas y la monarquía.

En relación a este proceso, resulta sorprendente que las historias de mártires presentaran la relación entre la Iglesia y su entorno pagano (en especial la monarquía) en términos de un "conflicto” irreductible (Van Rompay, 1995). Esta insistencia en el conflicto y la persecución enmascaraba las múltiples instancias de negociación entre la monarquía y una elite cristiana plenamente integrada a la aristocracia persa (McDonough, 2008a). Así, la proliferación de narrativas dedicadas a los "mártires” (más o menos legendarios) durante en las primeras décadas del siglo $\mathrm{V}$ daba cuenta del nuevo lugar de la Iglesia en relación a la monarquía. Al mismo tiempo, contribuyó a redefinir las bases sobre las que se asentaba el liderazgo comunitario a nivel local. Estas narraciones proyectaban el presente en el pasado, enmascarando la competencia (a veces negociada, a veces abiertamente conflictiva) por monopolizar el acceso a las fuentes tanto simbólicas como materiales de ese liderazgo, entre ellas las reliquias de los mártires. Esta competencia exigía la reconstrucción de la memoria comunitaria. Sin embargo, conviene recordar que no estamos frente a la competencia lineal entre la elite laica y la elite clerical por el control de los santuarios. Indudablemente, la emergencia de dichos santuarios apuntaló al episcopado como institución, pero al mismo tiempo parece haber sido parte de las estrategias de las elites locales.

A la luz de este proceso, el destino de las reliquias de Pōsī y Mārthā adquiere nueva relevancia. Como ya señalamos no se trata de una "competencia” por el control de los santuarios locales entre las elites laicas y una autoridad episcopal previamente constituida. Por el contrario, aunque el narrador presenta al obispo como investido de autoridad sobre las reliquias de los mártires, la insistencia en el "rescate" de los cuerpos 
expuestos por parte de laicos piadosos también confería una cierta legitimidad a la relación especial de ciertas familias con las reliquias de los santos. En ambos casos, éstas fueron fuente de identidad comunitaria y a la vez focos desde los que emana una autoridad espiritual que era objeto de negociación permanente.

A lo largo del siglo V y en especial en el siglo VI, una Iglesia progresivamente institucionalizada ejerció un control cada vez más estricto sobre las reliquias. La proliferación de historias de mártires asociadas a las principales sedes episcopales $\frac{44}{4}$ a lo largo del siglo $\mathrm{V}$ es testimonio de su importancia para afianzar la autoridad de un obispo y generar consensos hacia el interior de la comunidad. Esta tendencia episcopal a "monopolizar" del control sobre las reliquias se percibe en la evolución de los cánones de los sínodos. El canon II del sínodo de Mār Acacio (486 AD) inhibía la instalación de monjes dentro en las ciudades y les prohibía administrar los sacramentos a los laicos sin permiso episcopal. $\underline{45}$ El canon XX del sínodo de Mār Joseph (554 AD) suprimía esta prohibición, permitiendo la construcción de santuarios "dentro de las ciudades o en las proximidades de las ciudades”. $\underline{46}$ Pero, al mismo tiempo, prohibía que se administrara la eucaristía en dichos santuarios, dejando su administración en manos del clero bajo supervisión episcopal (Payne, 2011: 110). Aunque tal identificación no es del todo segura, resulta interesante notar que en ambos casos la principal razón esgrimida para la prohibición era que la presencia de santuarios dedicados a los mártires o monasterios sustraía a los laicos de su relación con el clero diocesano, poniendo directamente en cuestión la autoridad episcopal. $\underline{47}$ Por último, el canon XIV del sínodo de Mār Īšō‘yab (585) condenaba entre otras prácticas desviadas como la adivinación- a aquellos "que llevan imágenes de los huesos de los santos (damūthē degarmaī deqadīšè), o los mismos huesos de los santos (hānōn garmaī deqadīšē)” que visitan las casas de los fieles ("principalmente de mujeres disolutas”) y los entregan como amuletos a cambio de una recompensa. $\underline{48}$

Estas prohibiciones se complementaban con otras disposiciones que reforzaban el vínculo entre culto a las reliquias y autoridad episcopal. La fiesta en honor a los mártires locales no sólo eran ocasiones protocolares por las cuales los obispos asistían al arzobispo en la celebración litúrgica. Además, eran ocasiones en las que el Arzobispo de la metrópolis atendía cuestiones administrativas y disciplinarias con los obispos de su

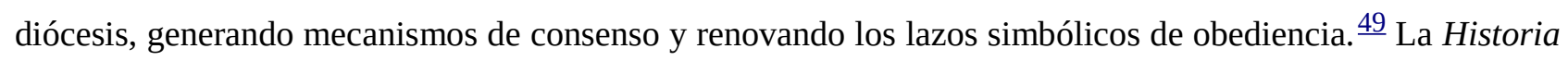
de Karkhā $d^{e} B \bar{e} t h S^{e} l \bar{k} k h$ hace referencia a un canon aprobado por un sínodo local que establecía que todos los obispos de la metrópolis debían asistir a la fiesta en conmemoración de los mártires de la ciudad. $\underline{50}$ El canon referido por la Historia de Karkhā revela la íntima relación entre las fiestas de los santos y la construcción de la autoridad de los metropolitanos.

Independientemente de los problemas interpretativos que presentan todos estos cánones, el testimonio de los sínodos de la Iglesia de Oriente confirma la importancia del culto a las reliquias en la resignificación del poder episcopal. Desarrollado bajo modelos occidentales en las décadas iniciales del siglo V el culto fue concomitante con un proceso de construcción de una autoridad que escapaba al control de las elites laicas pero que, paradójicamente lo hacía dependiente de ellas. Los cánones de los dos primeros sínodos de la Iglesia de Oriente $(410,420)$ se concentraron primariamente en la disciplina eclesiástica. Dichos cánones conferían al católico, los metropolitano y obispos variadas herramientas de control sobre el clero (participación en la consagración, institución de tribunales presididos por el católico y los metropolitanos, reunión periódica de sínodos generales y locales) al tiempo que tenían por efecto distinguir al clero (obispos, presbíteros y diáconos) de los laicos. $\frac{51}{}$ Los cánones de estos primeros sínodos tuvieron por efecto la inscripción del episcopado en una red supralocal (la metrópolis y el Catolicado de la Iglesia de Oriente) que redefinió y amplió la autoridad episcopal. Esto no supuso el final de la influencia de los linajes laicos. Pero se había agregado una nueva variable en la ecuación. Los cánones de los tres primeros sínodos se orientaron -junto con la ortodoxia nicena- a la disciplina clerical y a definir los aspectos prácticos de la jerarquía 
eclesiástica. En tal sentido, una parte sustancial de la autoridad del obispo escapaba de las relaciones locales y descansaba de su inscripción en una red horizontal que se desplegaba en el espacio. Esta circunstancia limitaba -pero no anulaba por completo- la capacidad de las elites laicas de influir sobre los obispos.

\section{Notas}

1 En persa Ērānšahr ī Šāhpūr, fundada por Sapor II quien la pobló con cautivos originarios del imperio romano. El obispo de Karkhā déLedān era sufragante del metropolita de Bēth Lapaṭ de la provincia eclesiástica de Juzistán (en la antigua Elam en el Irán sud-occidental) (Fiey, 1970: 123-130).

$\underline{2}$ Kōkhē era uno de los suburbios cercanos a la antigua capital helenística de Seleucia del Tigris (en persa Vēh Ardaxšēr) y que conformaban el complejo que rodeaba la capital de invierno sasánida: Ctesifón. El conjunto era conocido como Māḥōzē (en árabe Al-Madayn) i.e. "las ciudades”.

$\underline{3}$ Iglesia de Oriente ('edtā $d^{e}$ madn ${ }^{e} h \underline{a}$ ) era el nombre utilizado por la Iglesia del imperio persa sasánida para diferenciarse de la Iglesia de Occidente ('edtā $d^{e} m a$ 'rbā), es decir, la Iglesia del imperio romano. A partir del siglo V, el obispo primado (equivalente a los patriarcados) recibía el título de Católico. En el caso de Simeón, que vivió en el siglo IV, tal título es un anacronismo.

4 Estos "cautivos" (en siríaco b $b^{e}$ nay še bhìthā) eran los deportados de origen romano (o sus descendientes) que fueron trasladados durante las incursiones persas en territorio romano de los siglos III y IV. Aunque es imposible evaluar con exactitud la incidencia demográfica, cultural y económica de estos cautivos, es indudable que ocuparon un lugar central en el imaginario de la Iglesia persa. La identidad cultural de estos deportados parece haberse mantenido por varias generaciones y constituyeron una categoría especial que se diferenciaban de los cristianos locales. Sobre la relación entre las deportaciones y la expansión de la Iglesia persa ver Decret (1979), Jullien (2006) y Mosig-Walburg (2010), Smith (2016).

$\underline{5}$ La historia del martirio de Simeón se encuentra contenida en dos redacciones que se remontan a una fuente común compuesta a finales del siglo IV o principios del V. Una redacción larga (B), generalmente conocida como la Historia de Simeón (Smith, 2014: 68-211) y una recensión corta (A) conocida simplemente como el Martirio de Simeón (BHO: 1117) (Smith, 2014: 6-59). El Martirio de Simeón fue escrito pocos años antes y no pertenece a este ciclo. Sobre los diferentes testimonios del martirio (Wiessner, 1967: 40-94).

6 Llamado así en tanto el núcleo central del ciclo es la redacción larga (B), es decir la Historia.

$\underline{7}$ Por otra parte, es indudable que los materiales sobre los que se basaban estas historias se remontaran a tradiciones (orales y escritas) que ya circulaban en la segunda mitad del siglo IV. Así, a pesar de las sustanciales diferencias narrativas entre la Historia y Martirio de Simeón ambas se remontan a una fuente común, hoy perdida.

\section{으 Martirio de Pōsī: 208-209.}

9 Martirio de Mārthā: 233.

10 Martirio de Pōsī: 230.

\section{Historia de Simeón Bar Șabba‘ē: 210.}

12 Además de las referencias bíblicas el milagro del granizo guardaría cirta relación con el contexto religioso iranio. Cf. Bruns (2006: 203).

$\underline{13}$ i.e. una mujer consagrada a la vida ascética. Sobre esta institución propia del cristianismo siríaco ver (Vööbus, 1961), (Griffith, 1993). 
14 Martirio de Pōsī: 231.

15 Martirio de Pōsī: 232.

16 Cf. Bloch \& Parry (1989).

17 Literalmente “depósito” o todo aquello que es otorgado condicionalmente.

$\underline{18}$ Por supuesto, no debemos relacionarlo con nuestra noción moderna de soborno. Este concepto se refiere a todo don entregado a cambio de una contraprestación y, en consecuencia, es lo opuesto a la "bendición" desinteresada, Cf. Caner (2006: 357).

19 Martirio de Marthā: 240.

20 Historia de Simeón Bar Șabba‘ēe: 210.

21 La Gran Matanza de Bēth Hūzāyē: 253-254.

22 Martirio de los 120 mártires: 291.

23 Martirio de los 120 mártires: 295.

24 Cf. Martirio de 'Aqebšemāa: 378-379.

$2 \underline{5}$ Martirio de Narsaï: 171.

26 Mādīgān ī Hazār Dādastān: 96-101.

$\underline{27}$ Historia de Karkhā de Bēth Selōkh: 18-22.

$\underline{28}$ Historia de Karkhā de Bēth Selōkh: 22-25.

29 Synodicon Orientale: 357-359, 376-379.

$\underline{30}$ El rey Bahram V (420-438).

31 Martirio de Mārthā: 240-241.

$\underline{32}$ A lo largo del texto el martirio de Jacobo es comparado con el banquete nupcial.

33 Martirio de Jacobo el notario: 199-200.

34 Synodicon Orientale: 19-25.

35 Historia de Simeón Bar Șabba ‘ē: 78-80.

36 Historia de Simeón Bar Șabba‘ē: 84, 122.

$\underline{37}$ Historia de Karkhā deBēth $S^{e}$ lōkh: p. 24.

38 Martirio de 'Aqebšemā: 363.

$\underline{39}$ Historia de Simeón Bar Șabba ‘ē: 210. Resulta curioso que el autor nunca identifique a dichos obispos, lo que no es sorprendente ya que todos los obispos reunidos en la ciudad habían sido ejecutados.

40 Synodicon Orientale: 271-273.

41 Synodicon Orientale: 276-284.

42 Synodicon Orientale: 254-298.

$\underline{43}$ La ciudad de Martirópolis/ Maīpherqaț (hoy Silvan al sudeste de Turquía) estaba ubicada en la región de 
Arzanene, al sur de Armenia y en la frontera romano/persa.

44 En este conjunto podemos incluir, la lista de mártires de Bēth Garmaī (BHO: 807), el "Pasionario de Adiabene” (Peeters, 1925) y los relatos atribuidos al monje Abgar (Devos, 1965).

45 Synodicon Orientale: 55.

46 Synodicon Orientale: 106-107.

47 Synodicon Orientale: 55-56.

$\underline{48}$ Cf. Synodicon Orientale: 150.

49 Synodicon Orientale: 264.

$\underline{50}$ Historia de Karkhā $d^{e} B \bar{B} t h S^{e} l o ̄ k h:$ p. 44. Este canon guarda similitud con otros dos cánones de los sínodos de la Iglesia de oriente. Primero el canon VI del sínodo de Mār Isaac (410) -parafraseando el canon V del concilio de Nicea- establecía que los obispos debían reunirse con el Católico cada dos años en la capital imperial “cuando el rey se encuentre en la ciudad” (Synodicon Orientale: p. 25) Este canon fue reformado por el sínodo de Mār Baboī (497) que estableció que el sínodo debía tener lugar cada cuatro años (Synodicon Orientale: p. 64) en el mes de octubre.

51 Cf. Synodicon Orientale: 263-273, 278-280, 286-288.

\section{Bibliografía}

\section{Abreviaturas}

BHO: Peeters, P. (1910). Bibliotheca Hagiografica Orientalis. Bruselas: Socci Bollandiani.

AMS, Bedjan, P. (1891). Acta Martyrum et Sanctorum Syriace, 7 vol. II, París-Leipzig: Harrassowitz.

\section{Fuentes}

Historia de Simeón Bar Șabba'ē: Smith, K. (2014). The Martyrdom and History of Blessed Simeon Bar Șabba'e. Piscataway: Gorgias Press.

Historia de Karkhā de Bēth Selōkh: Francisco, H. (2016). La Historia de Karkhā de Bēth $S^{e} l \bar{k} k h$ y otros textos relativos a los mártires persas. Buenos Aires, IMHICIHU-CONICET.

Mādīgān ì Hazār Dādastān: Perikhanian, A. (1997). The Book of a Thousand Judgements a Sasanian Law book, Nueva York: Mazda Publishers.

La Gran Matanza de Bēth Hūzāyē: AMS II: 248-254.

Martirio de 'Aqebš̌ mā: AMS II: 351-396.

Martirio de los 120 mártires: AMS II: 291-295.

Martirio de Jacobo el notario: AMS IV: 189-200.

Martirio de Mārthā: AMS II: 233-241.

Martirio de Narsaī: AMS II: 170-180.

Martirio de Pōsī, AMS II: 208-232.

Synodicon Orientale: Chabot, J.B. (1902). Synodicon Orientale, París: Klincksieck. 


\section{Bibliografía seundaria}

Becker, A. (2014). Political Theology and Religious Diversity in the Sasanian Empire. en Herman, G. (ed.). Jews, Christians and Zoroastrians. Religious Dynamics in a Sasanian Context. Piscataway: Gorgias Press, pp. 7-25.

Bloch, M. \& Parry, J. (1989) Money and the Morality of Exchange. Cambridge: Cambridge University Press.

Boyce, M. (1968). The pious foundations of the Zoroastrians. Bulletin of the School of Oriental and African Studies, 31, pp. 270-289.

Brown, P. (1981) The Cult of the Saints. Its Rise and Function in Latin Christianity. Chicago: University of Chicago Press.

Brown, P. (1982). Relics and Social Status in the Age of Gregory of Tours. En: idem, Society and the Holy in Late Antiquity, 222-50. Berkeley: University of California Press.

Bruns, P. (2006). Reliquien und Reliquienverehrung in den syro-persischen Martyrerakten. Romische Quartalschrift fur Christliche Altertumskunde und Kirchengeschichte, 101, pp. 194-213.

Caner, D. (2006). Towards a Miraculous Economy Christian Gifts and Material "Blessings" in Late Antiquity. Journal of Early Christian Studies, 14, pp. 329-377.

Clark, E. A. (1982). Claims on the bones of Saint Stephen: the partisans of Melania and Eudocia. Church History 51.2, pp. 141-156.

Decret, F. (1979). Les conséquences sur le christianisme en Perse de l'affrontement des empires romain et sassanide. De Shâpûr Ier à Yazdgard Ier. Recherches Augustiniennes et Patristiques, 14, pp. 91-152.

Déroche, V. (1995). Études sur Léontios de Neápolis, Uppsala, Uppsala Universitet.

Devos, P. (1965). Abgar: hagiographe perse méconnu (début du V $\mathrm{V}^{\mathrm{e}}$ siècle). Analecta Bollandiana, 83: pp. 303-28.

Fiey, J.M. (1969). L'élam, la première des métropoles ecclésiastiques syriennes orientales. Meltho, 5, pp. 221-267.

Fiey, J.M. (1970). L'Élam, la première des métropoles ecclésiastiques syriennes orientales (suite). Parole de l'Orient, 1, pp. 123-153.

Fiey, J.M. (1986). La vie mouvementée des reliques dans l'orient. Parole de l'Orient, 13, pp. 183-196.

Finn, R. (2006). Almsgiving in the Later Roman Empire: Christian Promotion and Practice (313-450). Oxford: Oxford University Press, 2006.

Geary, P. (1988) Sacred commodities: the circulation of medieval relics, en: Appadurai, A. (ed.) The Social Life of Things: Commodities in Cultural Perspective. Cambridge: Cambridge University Press.

Jammo, S. (1995). Trois synodes, deux ecclésiologies de l'Eglise de l'Orient. Istina, 40, 140-148.

Jullien, C. (2006). La minorité chrétienne "grecque“ en terre d’Iran. En: Gyselen, R. (ed.) Chrétiens en terre d'Iran: implantation et acculturation. París: AAEI, pp. 105-142

Jullien, C. (2008). VI ${ }^{\mathrm{e}}$ siècle, un Temps de réformes en Iran. Échos dans l'Eglise syro-Orientale? Parole de l'Orient, 33, pp. 219-232.

Markus, R.A. (1994). How on Earth Could Places Become Holy? Journal of Early Christian Studies, 2, pp. 257-271. 
McDonough, S. (2006). A Question of Faith? Persecution and Political centralization in the Sasanian Empire of Yazdgard II (438-457 CE.). En: Drake, H.A. Violence, Victims, and Vindication in Late Antiquity. (pp. 6985). Aldershot: Ashgate.

McDonough, S. (2008a). Bishops or Bureaucrats?: Christian Clergy and the State in the Middle Sasanian Period. En: Kennet, D. \& Luft, P. (eds.) Current Research in Sasanian Archaeology, Art and History. Oxford: British Archaeological Reports, pp. 87-92

McDonough, S. (2008b). A Second Constantine?: The Sasanian King Yazdgard in Christian History and Historiography. Journal of Late Antiquity,1, pp. 127-140.

Mosig-Walburg, K. (2010). Deportationen römischer Christen in das Sasanidenreich durch Shapur I. und ihre Folgen - Eine Neubewertung. Klio, 92.1, pp. 117-156.

Payne, R. (2011). The emergence of martyrs' shrines in late antique Iran: conflict, consensus, and communal Institutions. En: Sarris, P., Dal Santo, M. \&.Booth, P. (eds.) An Age of Saints? Power, Conflict and Dissent in Early Medieval Christianity. (pp. 89-113). Leiden: Brill.

Payne, R. (2015). A State of Mixture Christians, Zoroastrians, and Iranian Political Culture in Late Antiquity. Berkeley: University of California Press.

Peeters, P. (1925). Le 'Passionaire d'Adiabène. Analecta Bollandiana, 43, pp. 261-304.

Smith, K. (2016). Constantine and the Captive Christians of Persia. Martyrdom and religious Identity in Late Antiquity. Berkeley: University of California Press.

Van Rompay, L. (1995). Impetuous Martyrs? The Situation of the Persian Christians in the Last Years of Yazdgard I (419-421). En Lambergis, M. \& Van Deun, P. (eds.) Martyrium in Multidisciplinary Perspective. Memorial Louis Reekmans. Lovaina: Peeters, pp. 363-375.

Vööbus, A. (1961). The Institution of the Benai Qeiama and Benat Qeiama in the Ancient Syrian Church. Church History, 30, pp. 19-27.

Wiessner, G. (1967). Zur Märtyrer-überlieferung aus der Christenverfolgung Schapurs II, Göttingen: Vandenhoeck \& Ruprecht. 